\title{
The Usefulness of Periareolar Zigzag Incision in Breast Conserving- Surgery in Breast Cancer Patients: Experience in a Single Institution
}

\author{
Seong Jun Lim, M.D. ${ }^{1}$, Hee Jeong Kim, M.D., Ph.D. ${ }^{1}$, Il Young Chung, M.D., Ph.D. ${ }^{1}$, Ji Sun Kim, M.D., Ph.D. ${ }^{1}$, \\ Sae Byul Lee, M.D., Ph.D. ${ }^{1}$, Jong Won Lee, M.D., Ph.D. ${ }^{1}$, Byung Ho Son, M.D., Ph.D. ${ }^{1}$, Sei Hyun Ahn, M.D., Ph.D. ${ }^{1}$, \\ Hak Hee Kim, M.D., Ph.D. ${ }^{2}$, Sung-Bae Kim, M.D., Ph.D. ${ }^{3}$, Gyung-Yub Gong, M.D., Ph.D. ${ }^{4}$, Beom Seok Ko, M.D., Ph.D. ${ }^{1}$ \\ ${ }^{1}$ Department of Surgery, ${ }^{2}$ Departement of Radiology, ${ }^{3}$ Department of Oncology, ${ }^{4}$ Department of Pathology, Asan Medical Center, University of Ulsan \\ College of Medicine, Seoul, Korea
}

Purpose: Various incision techniques have been used in breast-conserving surgery (BCS) to reduce scar formation, including the frequently used periareolar incision technique. However, its applicability in removing large-size tumors or those distant from the nipple has remained limited. We performed periareolar zigzag (P-Z) incision to address these problems in BCS and to improve cosmetic outcomes. Methods: Patients who underwent P-Z incision in BCS between January 2016 and November 2017 were retrospectively analyzed in terms of clinicopathological features and surgical findings. Factors affecting the positive margin were analyzed. Results: A total of 305 patients were reviewed. The patients presented with a median age of 51 years, mean tumor size $1.9 \mathrm{~cm}$, and mean tumor distance of $3.3 \mathrm{~cm}$ from the nipple. Intraoperative frozen biopsy and final pathologic findings showed $43(14.1 \%)$ and $7(2.3 \%)$ tumor-positive margins. There were no major complications associated with the surgery, and no re-operations were required due to bleeding or other reasons. Conclusion: The P-Z incision technique was used to achieve sufficient operative field during BCS, and large tumors or those distant from the nipple could be removed without any complications. This technique is considered an oncologically safe surgical technique resulting in good cosmetic outcomes.

Key Words: Margins of excision, Segmental mastectomy, Surgical wound

\section{INTRODUCTION}

Breast cancer screening programs, such as the mammography and breast ultrasonography, have been performed to increase the early detection and likelihood of performing a breast-conserving surgery (BCS) [1]. Because the prognosis in such cases is similar to that in patients receiving radiation therapy after BCS or mastectomy, BCS has become the standard of care in early breast cancer [2,3]. Patients and surgeons prefer to preserve breasts, whenever possible, using BCS as it preserves aesthetic outcomes and psychological aspects than with mastectomy [4]. However, several factors including scarring after surgery affect the satisfaction among patients that undergo BCS [5].

To reduce the scarring, several incision methods have been performed at inconspicuous sites, such as the periareolar region, inframammary fold, or the axilla, depending on the location of the tumor [6]

Correspondence: Beom Seok Ko, M.D., Ph.D.

Department of Surgery, Asan Medical Center, University of Ulsan College of Medicine, 88 Olympic-ro 43-gil, Songpa-gu, Seoul 05505, Korea

Tel: +82-2-3010-3510, Fax: +82-2-474-9027, E-mail: spdoctorko@gmail.com

Received: Oct 17, 2019 Revised: Nov 18, 2019 Accepted: Feb 18, 2020
While the small-sized tumors near the nipple can be easily excised through a periareolar incision, it is challenging to remove relatively large tumors or those distant from the nipple. To address this problem, we performed P-Z incision in BCS that has the following advantages. First, the incision line is not noticeable. Second, the tension is dispersed, leaving less scars. Third, a wider surgical field can be secured compared with a linear incision (Figure 1A). Furthermore, providing a wider surgical field should ensure oncologic safety and shorten the duration of surgery. Here, we present our experiences with breast cancer patients who underwent P-Zincision in BCS.

\section{METHODS}

\section{Study design}

Here, in our retrospective study at a single center, we reviewed the medical charts and pathology records, including the characteristics(age, stage, type axillary surgery, molecular subtype), and surgical and histopathological findings in breast cancer patients who underwent P-Z incision in BCS ( $\mathrm{n}=373)$, operated between January 2016 


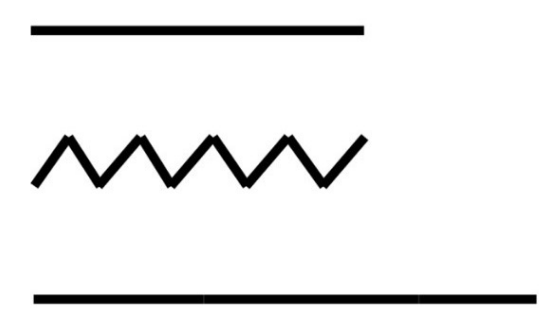

(A)
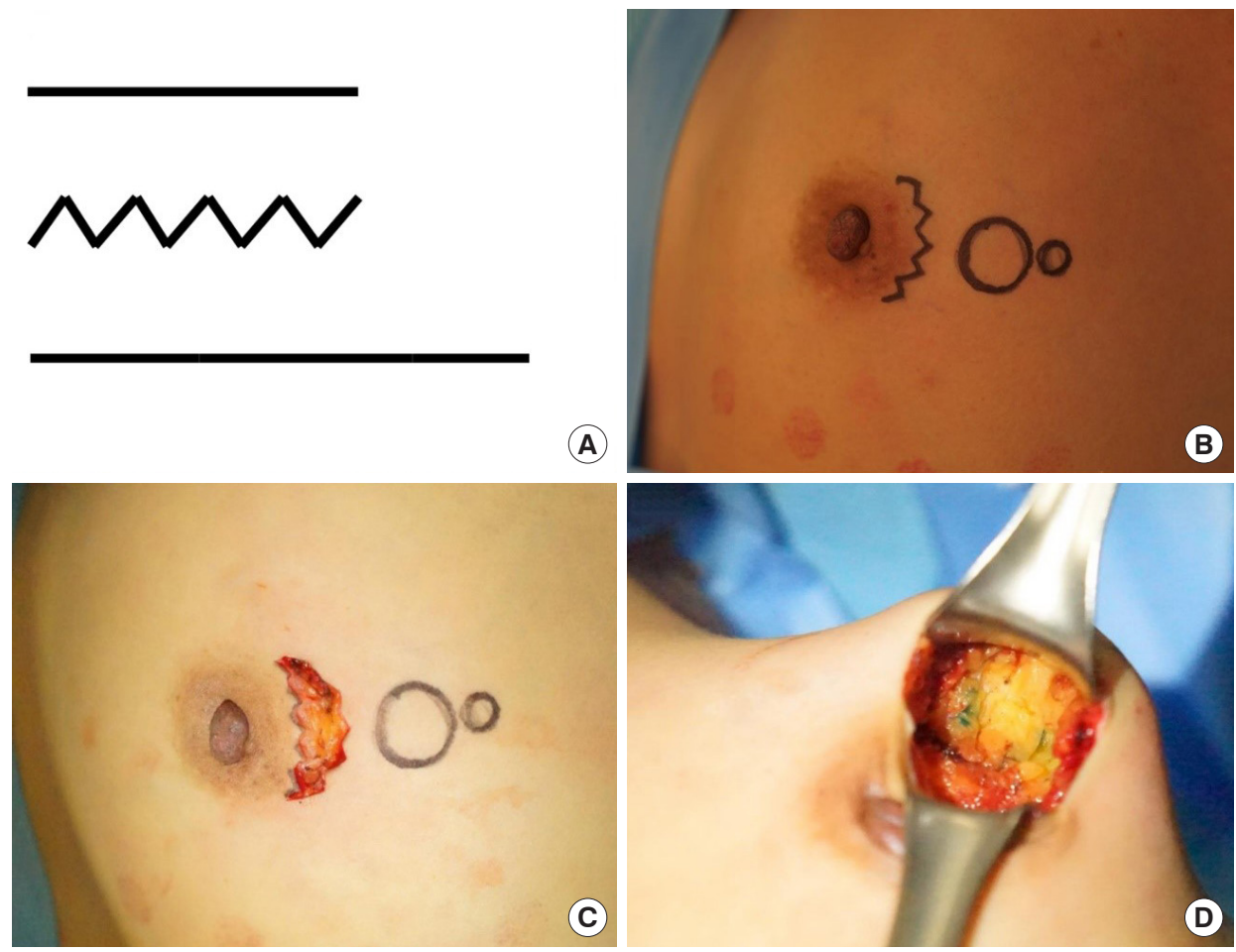

Figure 1. The schematic showing zigzag incision longer than linear incision (A), lesion and incision line design (B), initial status after periareolar zigzag incision (C), safety margin secured by dissection until reaching to the blue dye (D).

and November 2017. Patients who underwent neoadjuvant systemic therapy and those with operable distant metastasis were also included in this cohort. Further, patients with ductal carcinoma in situ (DCIS, $n=54)$, bilateral breast cancer $(n=9)$ and those who switched to mastectomy due to failure in BCS $(n=5)$ were excluded from the study. Surgery duration, margin status, tumor characteristics, and factors related to margin positivity were analyzed. The surgery duration was the time taken from skin incision till the end of the skin suture, and the time taken to obtain sentinel node biopsy (SNB) and resected frozen biopsy results was included. The absence of more breast tissue to be removed at the edge was considered a clear or negative margin, and the tissue analysis result was considered negative for lobular carcinoma in situ. Additionally, we assessed the surgical complications such as bleeding and infections. Statistical analysis was performed using arithmetic statistics for each patient, and the Pearson Chi-square test was used when comparing both groups. The study was approved by the Institutional Review Board of Asan Medical Center (IRB No. 2017-0463).

\section{Technique}

Under the effect of general anesthesia, the patient was placed in the supine position with the arm on the surgery side abducted toward the axillary side. The P-Z incision is designed based on the shape of the areola's boundary and is performed slightly outward if the areola is small. Before performing the skin incision, a radioisotope $(99 \mathrm{~m}$ Tc-phytate $0.25 \mathrm{mCi}[0.8 \mathrm{cc}]$ ) was injected around the areola for sentinel lymph node biopsy. In the case of patients whose tumors were not palpable, the extent of removal was determined using ultrasound to mark the area of the tumor on the skin, and the specimen removal was confirmed via intraoperative ultrasonography. A P-Z incision was performed along the areolar border in the direction of the tumor (Figure $1 \mathrm{~B}, 1 \mathrm{C})$. Blue dye infusion was performed at several sites and was removed before skin incision. After incision, we dissected the portion between the parenchyma and fat, approached the tumor boundary, and removed the tumor tissue including an appropriate safety margin (Figure 1D). SNB was performed depending on the extent of metastasis, except in patients who underwent axillary lymph node dissection (ALND). The removed specimen was tied at 3 o'clock and 12 o'clock position for directional orientation. To obtain a tumor-free margin, 
specimens were collected from several sites of the cavity wall and frozen biopsies were performed; additional resection was performed depending on the presence of a tumor. In patients that were expected to have a deformity due to the large size of the excised tissue, the surrounding glandular tissues were rearranged to fill the defect. After controlling the bleeding, a suture was applied to the zigzag edge and the surgery was completed.

\section{RESULTS}

A total of 305 invasive breast cancer patients were enrolled in the study; their clinicopathological findings are summarized in Table 1. Of these, 171 (56.1\%) were under 50 years old and 134 (43.9\%) were over 50 years old. Final histology examination results showed $286 \mathrm{pa}-$ tients (93.8\%) with invasive ductal carcinoma (IDC) 19 with invasive lobular carcinoma (ILC) (6.2\%). Based on the AJCC 7th edition, 146 Table 1. Patient and tumor characteristics $(n=305)$

\begin{tabular}{|c|c|}
\hline Characteristic & №. (\%) \\
\hline \multicolumn{2}{|l|}{ Age (yr) } \\
\hline$<50$ & $171(56.1)$ \\
\hline$\geq 50$ & $134(43.9)$ \\
\hline \multicolumn{2}{|l|}{ Pathology type } \\
\hline IDC & $286(93.8)$ \\
\hline ILC & $19(6.2)$ \\
\hline \multicolumn{2}{|l|}{ Stage } \\
\hline 1 & $146(47.9)$ \\
\hline$\|$ & $141(46.2)$ \\
\hline III & $15(4.9)$ \\
\hline IV & $3(1.0)$ \\
\hline \multicolumn{2}{|l|}{ Type axillary surgery } \\
\hline Sentinel node biopsy & $230(75.4)$ \\
\hline Axillary dissection & $74(24.3)$ \\
\hline No axillary surgery & $1(0.3)$ \\
\hline \multicolumn{2}{|l|}{ Histologic grade } \\
\hline I & $13(4.3)$ \\
\hline$\|$ & $211(69.2)$ \\
\hline III & $81(26.6)$ \\
\hline \multicolumn{2}{|l|}{ Nuclear grade } \\
\hline I & $13(4.3)$ \\
\hline$\|$ & $211(69.2)$ \\
\hline III & 81 (26.6) \\
\hline \multicolumn{2}{|l|}{ Subtype } \\
\hline $\operatorname{HR}(+), \operatorname{HER} 2(-)$ & $218(71.5)$ \\
\hline $\mathrm{HR}(+), \mathrm{HER} 2(+)$ & $37(12.1)$ \\
\hline $\operatorname{HR}(-), \operatorname{HER} 2(+)$ & $20(6.6)$ \\
\hline HR(-), HER2(-) & $30(9.8)$ \\
\hline
\end{tabular}

IDC = invasive ductal carcinoma; ILC = invasive lobular carcinoma; $\mathrm{HR}=$ hormone receptor; HER2 = human epidermal growth factor receptor 2 . patients (47.9\%) were in Stage I, 141 (46.2\%) were in Stage II, and 15 $(4.9 \%)$ and $3(1.0 \%)$ were in Stage III and IV, respectively. SNB was performed in 230 patients (75.4\%), and 74 (24.3\%) required ALND. Lumpectomy alone was performed in one patient. Thirteen patients (4.3\%) were of histology grade I, 211 (69.2\%) were of grade II and 81 (26.6\%) were of grade III. The tumor subtype was as follows; 218 patients (71.5\%) with $\mathrm{HR}(+) / \mathrm{HER} 2(-)$ status, 37 (12.1\%) with $\mathrm{HR}(+)$ / HER2(+) status, 20 (6.6\%) with HR(-)/HER2(+) status, and 30 (9.8\%) with HR(-)/HER2(-) status. Table 2 shows surgical specimen characteristics. The frozen margin status was positive in 43 patients (14.1\%) and negative in 262 (85.9\%). The permanent margin status was positive in seven patients (2.3\%) and negative in 298 (97.7\%). The mean surgery duration in the SNB group was $75.2 \mathrm{~min}$ (range, 32-340 min) and that in the ALND group was $89.3 \mathrm{~min}$ (range, 49-171 min).

Histology examination showed that the mean margin obtained was $1.2 \mathrm{~mm}$ (range, 0-10 mm). Specimen mean diameter was $5.5 \mathrm{~cm}$ (range, 0.9-15 cm), of which invasive tumors occupied a mean of 1.9 $\mathrm{cm}$ (range, $0-8.8 \mathrm{~cm}$ ). We considered frozen resection margin-positive or permanent resection margin-positive cases as a margin-positive group. Margin-positive and margin-negative groups were compared via univariate analysis (Table 3). There were no significant differences in age, tumor size, distance from the nipple to the tumor, nuclear grade, molecular subtype, or neoadjuvant chemotherapy. However, multifocality in the margin-positive group was significantly higher than that in the margin-negative group $(p=0.005)$. Contrary to the concern that it is challenging to obtain a safety margin if the tumor is located far from the nipple, there was no difference between the

Table 2. Surgical specimen characteristics

\begin{tabular}{lc}
\hline Characteristic & Mean \pm SD (range) \\
\hline Mean surgery duration (min) & $75.2 \pm 26.2(32-340)$ \\
SNB only & $89.3 \pm 24.7(49-171)$ \\
ALND & $5.5 \pm 2.0(0.9-15.0)$ \\
Specimen diameter (cm) & $1.9 \pm 1.1(0-8.8)$ \\
Tumor diameter (cm) & $3.3 \pm 1.8(0-9.0)$ \\
Distance from nipple to tumor (cm) & $1.2 \pm 1.1(0-10.0)$ \\
Distance from tumor to margin $(\mathrm{mm})$ & \\
Margin status (frozen, N (\%)) & $43(14.1)$ \\
Positive & $262(85.9)$ \\
Negative & $7(2.3)$ \\
Margin status (permanent, N (\%)) & $298(97.7)$ \\
Positive & \\
Negative &
\end{tabular}

$\mathrm{SNB}=$ sentinel node biopsy $; \mathrm{ALND}=$ axillary lymph node dissection . 
Table 3. Univariate analysis of resection margin positivity

\begin{tabular}{|c|c|c|c|}
\hline Characteristic & $\begin{array}{l}\text { Positive } \\
\text { margins } \\
(n=44)\end{array}$ & $\begin{array}{c}\text { Negative } \\
\text { margins } \\
(n=261)\end{array}$ & $p$-value \\
\hline \multicolumn{4}{|l|}{ Age (yr) } \\
\hline$\geq 50$ & 24 & 147 & \multirow[t]{2}{*}{0.826} \\
\hline$<50$ & 20 & 114 & \\
\hline \multicolumn{4}{|c|}{ Tumor size (diameter, cm) } \\
\hline$\geq 3$ & 42 & 251 & \multirow[t]{2}{*}{0.822} \\
\hline$<3$ & 2 & 10 & \\
\hline \multicolumn{4}{|l|}{ Multifocality } \\
\hline Yes & 22 & 186 & \multirow[t]{2}{*}{0.005} \\
\hline No & 22 & 75 & \\
\hline \multicolumn{4}{|c|}{ Distance nipple to tumor (median, $\mathrm{cm}$ ) } \\
\hline$\geq 3$ & 22 & 159 & \multirow[t]{2}{*}{0.173} \\
\hline$<3$ & 22 & 102 & \\
\hline \multicolumn{4}{|l|}{ Nuclear grade } \\
\hline 1,2 & 32 & 192 & \multirow[t]{2}{*}{0.908} \\
\hline 3 & 12 & 69 & \\
\hline \multicolumn{4}{|l|}{ Subtype } \\
\hline $\mathrm{HR}+/ \mathrm{HER} 2-$ & 27 & 191 & \multirow[t]{4}{*}{0.114} \\
\hline HR+/HER2+ & 9 & 28 & \\
\hline HR-/HER2+ & 5 & 15 & \\
\hline HR-/HER2- & 3 & 27 & \\
\hline \multicolumn{4}{|c|}{ Neoadjuvant chemotherapy } \\
\hline No & 41 & 234 & \multirow[t]{2}{*}{0.467} \\
\hline Yes & 3 & 27 & \\
\hline
\end{tabular}

$\mathrm{HR}=$ hormone receptor; $\mathrm{HER} 2$ = human epidermal growth factor receptor 2. two groups in terms of distance from the nipple. Twenty-one patients were treated using antibiotics within one month. Seven patients had postoperative seroma or hematoma but did not need surgery.

\section{DISCUSSION}

Breast cancer is the most common cancer in women worldwide [7]. Breasts are not only functional feeding organs for infants, but are also cosmetically important for women, and breasts should be preserved if possible. Compared with mastectomy, BCS provides better cosmetic and psychosocial outcomes [4]. Because patients treated with BCS or mastectomy followed by radiotherapy have similar outcomes, BCS has been opted as a standard surgical strategy $[2,3]$. Successful BCS involves excising complete tumor and tumor margin, together with preserving the normal shape and normal tissue of the breast as much as possible. However, despite adequate resection, a positive margin is often found. Previous reports suggest 15\%-47\% margin positivity in BCS [8]. Therefore, to circumvent this issue, the lesion including adjacent normal tissue should be completely excised at the time of BCS, although this affects the cosmetic outcome. If the size of the tumor is
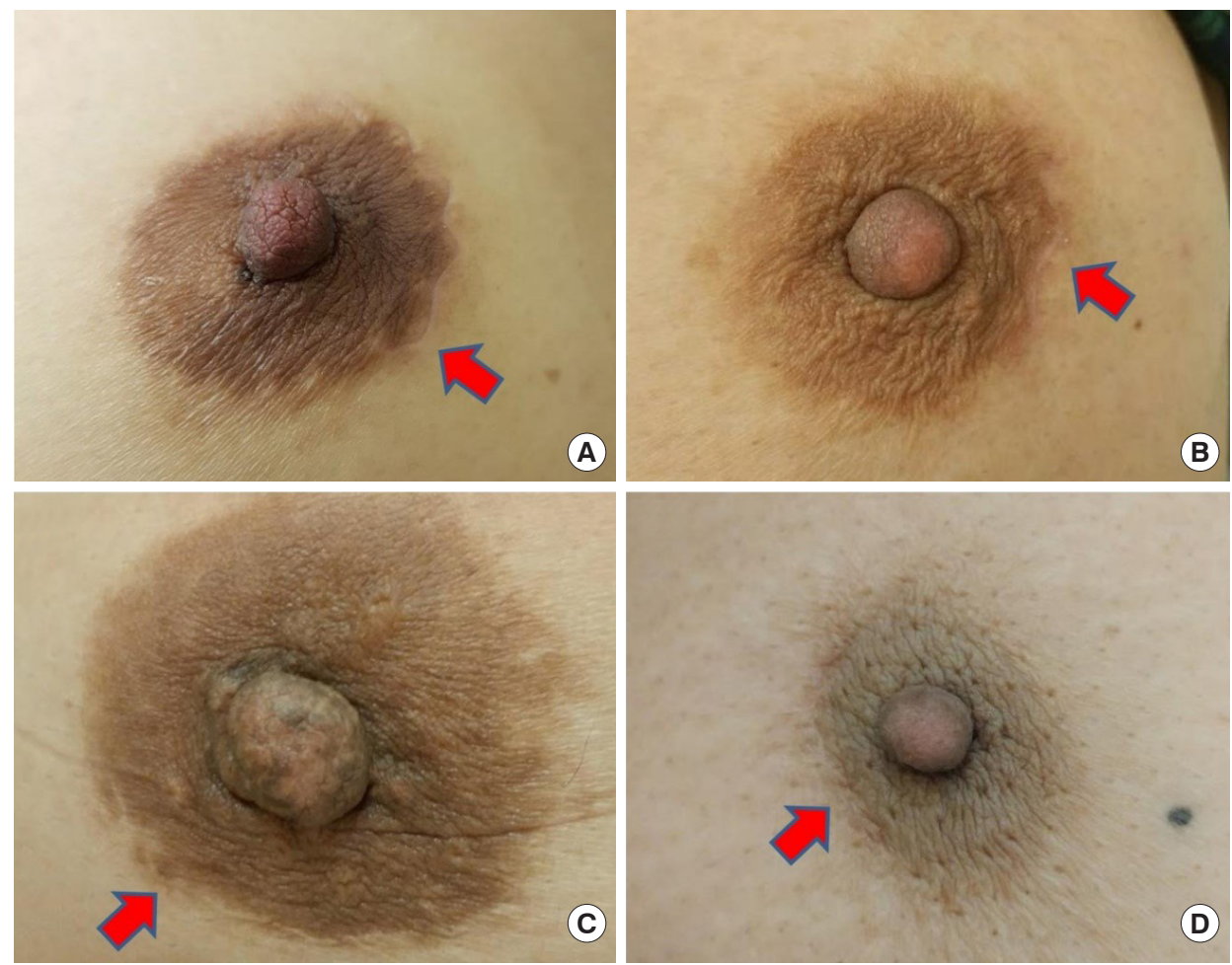

Figure 2. Patients have different type of skin color and areolar marin. Periareolar incision scar is very unnoticeable in various type of skin. 
relatively large than the breast, unwanted deformity and asymmetry may occur after BCS, leading to poor psychosocial outcomes in the patients $[9,10]$. Several methods of oncoplastic surgery, such as breast glandular tissue reposition, superior pedicle mammoplasty, racquet mammoplasty, and J-mammoplasty, have been performed to reduce the deformity and asymmetry of the breast [11]. However, these procedures can leave longer incisions and multiple scars during surgery [11]. In most cases of BCS, an incision is made on the skin directly above the tumor, where the incision scar sticks to the surgical site and scarring often occurs due to inversion. Moreover, if the incision is in a prominent area, it hampers the social activity, reducing quality of life and affecting prognosis in patients [12]. However, to hide the scars, an incision is made on the periareolar region, axilla, or inframammary folds [6]. Further, endoscopic BCS has been conducted to address these problems and several studies on its usefulness have been reported [13]. If the tumor is large or located far from the nipple, complete removal of the tumor is often challenging in the periareolar approach due to a narrow field of view. When the length of the incision is insufficient, a zigzag incision is commonly used, and because the tension is dispersed, organ undergoes less scarring than due to linear incisions, and the $\mathrm{P}-\mathrm{Z}$ incision can be used in augmentation mammoplasties [14]. Gryskiewicz JM, Hatfield AS have reported that a P-Z incision could reduce the complications in terms of cosmetic aspects, such as delay in healing, hypertrophic scars, and pigmentation alterations [15]. In our study, most of the patients showed good cosmetic outcomes several months after surgery (Figure 2). Carvajal and Echeverry et al. have reported the successful insertion of breast implants using a semicircular P-Z incision technique in women with an areolar diameter of less than $3 \mathrm{~cm}$. In patients with small areolae or large tumors, the donut mastopexy (round block) resection technique is helpful, and in our study, the P-Z incision enabled tumor removal without any problems [16].

However, our study has a few limitations. First, it was retrospective and conducted in a single institution. Second, outcome was not compared with patients that underwent BCS with other incision techniques. Third, cosmetic aspects were not evaluated using questionnaires addressing patient satisfaction. However, the tumor-free resection margin rate, surgery duration, and postoperative complications were similar to those in previous studies. Moreover, the cosmetic outcomes were better than those of other incision techniques.
The use of the P-Z incision technique in BCS ensures that sufficient operative field is obtained, so that larger tumors or tumors distant from the nipple can be removed relatively easily. Additionally, scarring can be reduced with good cosmetic outcomes.

\section{CONFLICT OF INTEREST}

The authors declare that they have no competing interests.

\section{REFERENCES}

1. Marmot MG, Altman DG, Cameron DA, Dewar JA, Thompson SG, Wilcox M. The benefits and harms of breast cancer screening: an independent review. Br J Cancer 2013;108:2205-40.

2. Early breast cancer trialists' collaborative group. Effects of radiotherapy and surgery in early breast cancer: an overview of the randomized trials. N Engl J Med 1995;333:1444-56.

3. Fisher B, Anderson S, Bryant J, Margolese RG, Deutsch M, Fisher ER, et al. Twenty-year follow-up of a randomized trial comparing total mastectomy, lumpectomy, and lumpectomy plus irradiation for the treatment of invasive breast cancer. N Engl J Med 2002;347: 1233-41.

4. Janni W, Rjosk D, Dimpfl TH, Haertl K, Strobl B, Hepp F, et al. Quality of life influenced by primary surgical treatment for stage I-III breast cancer long-term follow-up of a matched-pair analysis. Ann Surg Oncol 2001;8:542-8.

5. Haloua MH, Krekel NM, Jacobs GJ, Zonderhuis B, Bouman MB, Buncamper ME, et al. Cosmetic outcome assessment following breast-conserving therapy: a comparison between BCCT. core software and panel evaluation. Int J Breast Cancer 2014;2014:716860.

6. Holmes DR, Schooler W, Smith R. Oncoplastic approaches to breast conservation. Int J Breast Cancer 2011;2011:303879.

7. Ghoncheh M, Pournamdar Z, Salehiniya H. Incidence and mortality and epidemiology of breast cancer in the world. Asian Pac J Cancer Prev 2016;17:43-6.

8. Ananthakrishnan P, Balci FL, Crowe JP. Optimizing surgical margins in breast conservation. Int J Surg Oncol 2012;2012:585670.

9. Clough KB, Cuminet J, Fitoussi A, Nos C, Mosseri V. Cosmetic sequelae after conservative treatment for breast cancer: classification and results of surgical correction. Ann Plast Surg 1998;41:471-81. 
10. Waljee JF, Hu ES, Ubel PA, Smith DM, Newman LA, Alderman AK. Effect of esthetic outcome after breast-conserving surgery on psychosocial functioning and quality of life. J Clin Oncol 2008;26: $3331-7$.

11. Clough KB, Kaufman GJ, Nos C, Buccimazza I, Sarfati IM. Improving breast cancer surgery: a classification and quadrant per quadrant atlas for oncoplastic surgery. Ann Surg Oncol 2010;17:1375-91.

12. Kim MS, Rodney WN, Reece GP, Beahm EK, Crosby MA, Markey MK. Quantifying the aesthetic outcomes of breast cancer treatment: assessment of surgical scars from clinical photographs. J Eval Clin Pract 2011;17:1075-82.
13. Lee EK, Kook SH, Park YL, Bae WG. Endoscopy-assisted breast-conserving surgery for early breast cancer. World J Surg 2006;30:957-64

14. Lee EJ. Periareolar approach for augmentation mammoplasty. J Korean Soc Aesthetic Plast Surg 2009;15:105-15.

15. Gryskiewicz JM, Hatfield AS. "Zigzag” wavy-line periareolar incision. Plast Reconstr Surg 2002;110:1778-83; discussion 84.

16. Masetti R, Pirulli PG, Magno S, Franceschini G, Chiesa F, Antinori A. Oncoplastic techniques in the conservative surgical treatment of breast cancer. Breast Cancer 2000;7:276-80. 